\title{
Revisiting faultline conceptualization: measuring faultline strength and distance
}

\author{
Elaine L. Zanutto • Katerina Bezrukova • \\ Karen A. Jehn
}

(C) Springer Science+Business Media B.V. 2010

\begin{abstract}
The purpose of this research is to develop a conceptually and methodologically sound measure of group faultlines (demographic alignment of members along multiple attributes within a group). This measure takes into account the concept of faultline strength (the extent of a demographic alignment across members within a group) and, thus far neglected in past work, the concept of faultline distance. This faultline distance measure reflects how far apart the emerging subgroups are on demographic characteristics. This new, more elaborate conceptualization of faultlines is validated by presenting a number of hypothetical examples that demonstrate the distinct properties of faultline measures. We also validate our measures by empirically examining the relationships between faultline strength and distance, and active, or perceived, faultlines.
\end{abstract}

Keywords Faultline measure $\cdot$ Faultline strength $\cdot$ Faultline distance

\section{Introduction}

The questions about whether and how group composition affects processes and performance have received substantial attention over the last few decades. Of particular relevance, there have been methodological issues of how best to measure diversity in workgroups

Portions of this paper were presented at the Academy of Management Meeting 2004, New Orleans, LA.

E. L. Zanutto

National Analysts Worldwide, 1835 Market Street, 25th Floor, Philadelphia, PA 19103-2984, USA

e-mail: ezanutto@nationalanalysts.com

K. Bezrukova $(\varangle)$

Department of Psychology, Santa Clara University, 500 El Camino Real, Santa Calra, CA 95053, USA

e-mail: ybezrukova@scu.edu

K. A. Jehn

Melbourne Business School,

200 Leicester Street, Carlton, Victoria 3053, Australia

e-mail: k.jehn@mbs.edu

URL: http://works.bepress.com/etty_jehn 
(e.g., Bedeian and Mossholder 2000; Riordan and Shore 1997). Prior operationalizations of diversity have been often criticized because these measures mostly focused on member distribution on one attribute at a time. For example, three different indexes for measuring group diversity have been used in the past: index of heterogeneity (Blau 1977), diversity or entropy index (Teachman 1980), and coefficient of variation (Allison 1978). Essentially, all three measures of group diversity assess the proportion of a group that has a particular demographic attribute. Of course, some attempts to take into account the combined effects of multiple demographic characteristics have been made (e.g., Jehn et al. 1999; Polzer et al. 2002); however, they were based on statistical aggregation (constructing aggregated dispersion measures by averaging across demographic variables) rather than on group and organizational theories about how the characteristics may act together.

Most recently, there have been a few attempts to take into account the cumulative proportions of variance across demographic variables. This work has been guided by faultline framework that reasons that the compositional dynamics of interacting multiple attributes may affect group processes more than separate demographic characteristics (Lau and Murnighan 1998). According to this framework, group faultlines are hypothetical dividing lines that split a group into relatively homogeneous subgroups based on the group members' demographic alignment along one or more attributes (Lau and Murnighan 1998). Group members who share similar demographic characteristics (e.g., female, White, high school education) align together creating homogeneous subgroups within a group. Just as the strength of a geological fault increases with the number of layers it cuts through, the strength of a group faultline increases as the number of attributes along which two subgroups align increases. An example of a group with a strong faultline would be a four-person group consisting of two White male employees who are 21 years old and two Black female employees who are 50 years old (see Table 1, Group 1). In this group, the demographic alignment across members is clear because two homogenous subgroups may emerge based on group members' similarities in gender, race, and age; according to Lau and Murnighan (1998), there is a strong faultline within the group. An example of a group with weak faultline strength would be a four-person group consisting of one 21-year-old Asian female, one 21-year old White male, one 25-year-old Black female, and one 35-year-old Asian male (see Table 1, Group 2). In this latter group, the demographic alignment across members is not as clear as in the first example and faultline strength is weak because two different subgroup possibilities exist: those based on gender or age.

A number of potential challenges have been associated with a partially inadequate conceptualization of faultlines, an obscurity of faultline operationalization, and a lack of a sound method for quantifying such group splits (Trezzini 2006). For example, prior theorizing about faultlines has focused on the concept of faultline strength [defined as the extent of demographic alignment across members within a group (e.g., Lau and Murnighan 1998; Thatcher et al. 2003)]. Yet, another important aspect of faultlines-differences or distance between aligned subgroups-has been often ignored. In this paper, we introduce the concept of faultline distance that reflects the extent to which subgroups formed by faultlines diverge as a result of accumulated differences across them. Take another group as an example, which also has the same faultline strength as the group 1 above but a very different faultline distance: in this group, the two Black females are 30 years old and the two White males are 21 years old. In this example, the two members of age 30 are closer in age to two members of the opposing faultline subgroup than the two members of age 50 in our first group (see Table 1, Group 3). While both groups have similar faultline strength, the first group will have larger faultline distance. We thus, propose that given the varying 
Table 1 Examples of groups with strong and weak faultlines

\begin{tabular}{|c|c|c|c|c|c|c|c|}
\hline Group No. & Member A & Member B & Member C & Member D & L\&M faultline strength ${ }^{a}, b$ & $\mathrm{Fau}^{\mathrm{c}}$ & Distance $^{\mathrm{c}}$ \\
\hline \multirow[t]{3}{*}{1} & White & White & Black & Black & Strong ( 3 align, 1 way) & 1.00 & 2.03 \\
\hline & Male & Male & Female & Female & & & \\
\hline & 21 & 21 & 50 & 50 & & & \\
\hline \multirow[t]{3}{*}{2} & Asian & White & Black & Asian & Weak (1 align, 3 ways) & 0.51 & 1.15 \\
\hline & Female & Male & Female & Male & & & \\
\hline & 21 & 21 & 25 & 35 & & & \\
\hline \multirow[t]{3}{*}{3} & White & White & Black & Black & Strong ( 3 align, 1 way) & 1.00 & 1.48 \\
\hline & Male & Male & Female & Female & & & \\
\hline & 21 & 21 & 30 & 30 & & & \\
\hline
\end{tabular}

a With the number of identified attributes fixed at three, faultline strength, as defined by Lau and Murnighan (1998), is determined here by the number of demographic attributes that align (denoted as "align") and the possible ways to subdivide the group on the basis of these attributes (denoted as "ways")

${ }^{b}$ We use the following classification of faultline strength, based on the maximum number of characteristics that align: $1=$ weak, $2=$ medium, $3=$ strong

${ }^{\mathrm{c}}$ Here, race and gender are categorical. Age is continuous. The data are rescaled so that all of these are equivalent: 20 year difference in age, difference in gender, difference in race

differences in age, the group composition and processes of these two groups will be very different. ${ }^{1}$

Faultline strength, as defined by faultline framework, captures how many demographic attributes align within a group or, in other words, how cleanly a group may split into two homogeneous subgroups (emphasis on similarities). Faultline distance, however, reflects the extent to which subgroups diverge as a result of accumulated differences across aligned subgroups (emphasis on differences). In our example, two members of age 21 are closer in age to two members of an opposing faultline of age 30 than of two members of age 50. According to the literature on generational diversity (Arsenault 2004), members who are more distant in age will have different interests and will find it harder to relate to members of an opposing subgroup (e.g., discussions about retirement packages may not be equally attractive to all members). Thus, while groups may have similar faultline strength, strength, as it is defined by the theory, does not consider the fact that the subgroups in one group can be much farther apart than the subgroups in another group and hence, interactions and subsequent behaviors and outcomes will differ. Our concept of distance takes this into account and provides a metric of how far apart (conceptually different) these resulting subgroups are. We believe that mechanisms behind strength and distance are different and how the two constructs interact will be key. We propose that when there is an effect of faultline strength, faultline distance will exacerbate the strength effect. The purpose of this study therefore, is to develop a conceptually and methodologically reliable measure of faultlines that would take into account both faultline strength and distance.

Another criticism of past work on faultlines is that most faultline research focuses on potential faultlines (Gibson and Vermeulen 2003; Lau and Murnighan 2005; Li and Hambrick 2005; Molleman 2005; Sawyer et al. 2006) and does not examine whether members actually

\footnotetext{
1 While faultine distance seems to most simply refer to differences in age, tenure (years of experience), and other continuous variables, we argue that distance is also applicable for categorical variables. For example, if group 1 has two White members and two Asian members and group 2 has four White members, group 1 has a nonzero faultline distance between subgroups, while group 2 does not, which would be captured by the distance component of our faultline concept.
} 
Table 2 Examples of faultline measures for groups with four categorical variables

\begin{tabular}{|c|c|c|c|c|c|c|c|}
\hline $\begin{array}{l}\text { Group } \\
\text { No. }\end{array}$ & Member A & Member B & Member C & Member D & $\begin{array}{l}\text { L\&M Faultline } \\
\text { Strength }\end{array}$ & $\mathrm{Fau}^{*}$ & Distance* \\
\hline \multirow[t]{4}{*}{1} & White & White & White & White & None & 0 & 0 \\
\hline & Male & Male & Male & Male & & & \\
\hline & $20 \mathrm{~s}$ & $20 \mathrm{~s}$ & $20 \mathrm{~s}$ & $20 \mathrm{~s}$ & & & \\
\hline & Sales & Sales & Sales & Sales & & & \\
\hline \multirow[t]{4}{*}{2} & White & Black & Asian & Native & $\begin{array}{l}\text { Weak } \\
\text { (1 align, } 1 \text { way) }\end{array}$ & 0.45 & 1.58 \\
\hline & Male & Female & Female & Male & & & \\
\hline & $20 \mathrm{~s}$ & $30 \mathrm{~s}$ & $40 \mathrm{~s}$ & $50 \mathrm{~s}$ & & & \\
\hline & Secretary & Sales & Plant manager & Technician & & & \\
\hline \multirow[t]{4}{*}{3} & White & White & Asian & Asian & $\begin{array}{l}\text { Medium } \\
\quad(2 \text { align, } 1 \text { way) }\end{array}$ & 0.60 & 1.73 \\
\hline & Male & Male & Female & Female & & & \\
\hline & $50 \mathrm{~s}$ & $30 \mathrm{~s}$ & $40 \mathrm{~s}$ & $20 \mathrm{~s}$ & & & \\
\hline & Plant manager & Sales & Secretary & Clerical staff & & & \\
\hline \multirow[t]{4}{*}{4} & White & White & Black & Black & $\begin{array}{l}\text { Strong } \\
\text { (3align, } 1 \text { way) }\end{array}$ & 0.78 & 1.87 \\
\hline & Male & Male & Female & Female & & & \\
\hline & $30 \mathrm{~s}$ & $30 \mathrm{~s}$ & $20 \mathrm{~s}$ & $20 \mathrm{~s}$ & & & \\
\hline & Plant manager & Technician & Clerical staff & Sales & & & \\
\hline \multirow[t]{4}{*}{5} & Asian & Asian & Black & Black & $\begin{array}{l}\text { Very strong } \\
\text { (4 align, } 1 \text { way) }\end{array}$ & 1.00 & 2.00 \\
\hline & Female & Female & Male & Male & & & \\
\hline & $20 \mathrm{~s}$ & $20 \mathrm{~s}$ & $50 \mathrm{~s}$ & $50 \mathrm{~s}$ & & & \\
\hline & Sales & Sales & Executive & Executive & & & \\
\hline \multirow[t]{4}{*}{6} & White & Black & White & Black & $\begin{array}{l}\text { Medium } \\
\quad \text { (2 align, } 2 \text { ways) }\end{array}$ & 0.50 & 1.41 \\
\hline & Male & Female & Male & Female & & & \\
\hline & $50 \mathrm{~s}$ & $20 \mathrm{~s}$ & $20 \mathrm{~s}$ & $50 \mathrm{~s}$ & & & \\
\hline & Plant manager & HR manager & HR manager & Plant manager & & & \\
\hline \multirow[t]{4}{*}{7} & White & White & Black & Black & $\begin{array}{l}\text { Weak } \\
\text { (1 align, } 2 \text { ways) }\end{array}$ & 0.40 & 1.41 \\
\hline & Male & Female & Female & Male & & & \\
\hline & $20 \mathrm{~s}$ & $30 \mathrm{~s}$ & $40 \mathrm{~s}$ & $50 \mathrm{~s}$ & & & \\
\hline & Plant manager & Sales & HR manager & Technician & & & \\
\hline \multirow[t]{4}{*}{8} & White & Black & White & Black & $\begin{array}{l}\text { Weak } \\
\text { (1 align, } 3 \text { ways) }\end{array}$ & 0.33 & 1.22 \\
\hline & Male & Female & Female & Male & & & \\
\hline & $20 \mathrm{~s}$ & $20 \mathrm{~s}$ & $50 \mathrm{~s}$ & $50 \mathrm{~s}$ & & & \\
\hline & Plant manager & Sales & Secretary & Supervisor & & & \\
\hline
\end{tabular}

*Fau strength and distance are calculated treating age as categorical (20s, 30s, 40s, 50+). This corresponds roughly with the implicit categories used by Lau and Murnighan (1998) 
perceive the subgroup splits. Potential faultlines refer to hypothetical dividing lines that split a group into subgroups based on demographic alignment across members (Lau and Murnighan 1998). These demographic attributes may explain variance in attitudes and behavior; for example, individuals tend to identify and act in the ways that are consistent with their respective demographic grouping only because they happen to belong to that demographic group. This study then adds to the literature on faultlines by distinguishing between potential and active faultlines (members' subjectively experienced perceptions of splits). Whereas potential faultlines are based on the objective demographics of group members and their alignment, active group faultlines exist when the members perceive and behave as if they are two separate, different (and potentially even opposed) subgroups. We believe that it is critical to examine what the members perceive regarding the demographic composition within the group as this is the foundation for future interactions among group members. Thus, the present study also examines the relationship between potential faultlines and active faultlines using the data on 50 groups.

\section{Measuring faultlines}

The development of our faultline measures was motivated by Lau and Murnighan (1998) original faultline framework suggesting that the alignment of multiple demographic attributes can potentially subdivide a group. It is important to note that our faultline measures take into account cumulative proportions of variance across demographic variables; this makes it different from a simple aggregate measure in that it estimates how well the variability within the group can be explained by the presence of different clusters within the group for comparison with other measures (see Appendix 1 and also http://webpages.scu. edu/ftp/bezrukova/faultlines.htm). We adapted our faultline measures from the multivariate statistical clustering analysis literature (e.g., Jobson 1992; Morrison 1967; Sharma 1996). The goal of statistical clustering analysis is to classify a set of observations, each of which has measurements on several variables, into a small number of groups such that observations in the same group are "similar" and observations in different groups are "different". This is essentially the same goal we have in trying to identify potential faultlines within a group. As a result, we measure the strength of faultline splits using a multivariate measure of group similarities over several variables taken from the statistical cluster analysis literature (Jobson 1992). This statistic measures the degree of alignment or correlation of attributes within the resulting subgroups. We measure the degree of difference between two subgroups using a multivariate distance score taken from the multivariate statistical cluster analysis (e.g., Morrison 1967; Jobson 1992; Sharma 1996) that is calculated as the distance between subgroup centroids (the Euclidean distance between the two sets of average).

Although it is possible for a faultline to split the group into three or more subgroups, we focus on measuring faultlines that split the group into two subgroups. These are probably the most common type of splits in groups of small to moderate size, and possibly the most important since they are stronger (Lau and Murnighan 1998) and therefore, probably have more impact on members' interaction than splits into three or more subgroups. Possible extensions of our measures to faultlines that split the group into three or more subgroups are discussed in the discussion section of our paper. Our goal thus, is two-fold; first, we operationalize the concept of faultline strength and create a numerical score for each group that reflects the degree of faultline strength, accommodating both continuous and categorical characteristics, with larger scores indicating greater strength. For practical purposes, we focus on measuring 
the strongest faultline split, although our measure can be used to measure the strength of all faultlines in a group.

Second, we extend our operationalization of faultlines by measuring faultline distance along the strongest faultline split (our faultline measure includes one score for strength, one score for distance). This measure of faultline strength and distance is free from any judgment as to whether or not the faultline is strong enough "to matter." In other words, it is free of any preconceived notion as to how strong a potential faultline has to be to make it likely to be an active faultline. In this way, issues of measuring faultlines can be kept separate from issues of determining the impact of those faultlines (unlike, for example, Barkema and Chvyrkov (2003) who first make a judgment as to whether a faultline is strong enough to be considered to exist in a group before measuring that faultline). We assume in our faultline measures that the analysts can propose a reasonable system for equating differences on continuous and categorical characteristics (e.g., the impact on a faultline of a difference of 20 years in age is equivalent to a difference in gender). Although this requires subjective decisions by the analysts, such decisions are unavoidable when combining continuous and categorical characteristics (Gibson and Vermeulen 2003; Shaw 2004), and researchers who are concerned about the sensitivity of their results to these assumptions, can repeat their analyses under several different equating assumptions. Finally, we verify the connection of potential faultlines to active or perceived faultlines.

\subsection{Measuring faultline strength}

We measure faultline strength through a statistic, Fau, first used by Thatcher et al. (2003), but developed in more detail here. This statistic measures faultline strength as the proportion of total variation in overall group characteristics explained by the strongest group split. More technically, this is accomplished by calculating the ratio of the between group sum of squares to the total sum of squares. Fau is always larger than zero and less than or equal to one, with larger values indicating greater faultline strength. Calculating Fau can be viewed as a two-step process. The first step is to calculate:

$$
\text { Fau }_{g}=\left[\frac{\sum_{j=1}^{p} \sum_{k=1}^{2} n_{k}^{g}\left(\bar{x}_{\cdot j k}-\bar{x}_{\cdot j \cdot}\right)^{2}}{\sum_{j=1}^{p} \sum_{k=1}^{2} \sum_{i=1}^{n_{k}^{g}}\left(\bar{x}_{i j k}-\bar{x}_{\cdot j \cdot}\right)^{2}}\right] g=1,2, \ldots S,
$$

where $x_{i j k}$ is the value of the $j^{\text {th }}$ characteristic of the $i^{t h}$ member of subgroup $k, \bar{x}_{\cdot j .}$, is the overall group mean of characteristic $j, \bar{x}_{. j k}$ is the mean of characteristic $j$ in subgroup $k$, and $n_{k}^{g}$ is the number of members of the $k^{t h}$ subgroup $(k=1,2)$ under split $g$. The second step is to calculate the maximum value of $F a u_{g}$ over all possible splits $g=1,2, \ldots \mathrm{S}$ (or, to avoid splits involving a subgroups consisting of a single member, we can maximize over all splits where each subgroup contains at least two members). ${ }^{2}$

To include categorical variables in the Fau measure it is necessary to recode them into a series of dummy variables. More specifically, a categorical variable with $c$ categories, such as race or occupation, should be recoded as $c$ dummy variables (Jobson 1992, p. 502). The following example illustrates why it is necessary to use all c dummy variables (not c-1). Consider a three-category variable for industry: Agriculture, Banking, and Computer Technology. Using three dummy variables to recode the industry variable, the Euclidean distance (the difference measure using in Fau ) between an Agricultural company and a Computer Technology company is, ignoring all other characteristics, $\sqrt{(1-0)^{2}+(0-0)^{2}+(0-1)^{2}}=\sqrt{2}$.

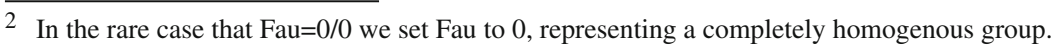


Table 3 Examples of faultline measures in groups with categorical and continuous variables that showing that groups with the same faultline strength can have different faultline distance

\begin{tabular}{|c|c|c|c|c|c|c|c|}
\hline $\begin{array}{l}\text { Group } \\
\text { No. }\end{array}$ & Member A & Member B & Member C & Member D & Faultline Strength & Fau & Distance \\
\hline \multirow[t]{3}{*}{$1^{*}$} & White & Black & White & Black & \multirow[t]{3}{*}{$\begin{array}{l}\text { Strong/Moderate ( } 2 \text { align, } \\
1 \text { way; } 1 \text { align, } 1 \text { way) }\end{array}$} & \multirow[t]{3}{*}{0.75} & \multirow[t]{3}{*}{2.26} \\
\hline & Female & Male & Male & Female & & & \\
\hline & Age $=75$ & Age $=32$ & Age $=18$ & Age $=56$ & & & \\
\hline \multirow[t]{3}{*}{$2 *$} & White & Black & White & Black & \multirow[t]{3}{*}{$\begin{array}{l}\text { Strong/Moderate ( } 2 \text { align, } \\
1 \text { way, } 1 \text { align, } 1 \text { way) }\end{array}$} & \multirow[t]{3}{*}{0.75} & \multirow[t]{3}{*}{1.72} \\
\hline & Female & Male & Male & Female & & & \\
\hline & Age $=65$ & Age $=35$ & Age $=37$ & Age $=63$ & & & \\
\hline \multirow[t]{3}{*}{3} & White & Black & Black & White & \multirow[t]{3}{*}{ Strong ( 2 align, 1 way) } & \multirow[t]{3}{*}{1.00} & \multirow[t]{3}{*}{1.73} \\
\hline & Male & Female & Female & Male & & & \\
\hline & Engineer & QA tester & QA tester & Engineer & & & \\
\hline \multirow[t]{3}{*}{4} & White & Black & Black & White & \multirow[t]{3}{*}{ Strong ( 2 align, 1 way) } & \multirow[t]{3}{*}{1.00} & \multirow[t]{3}{*}{1.41} \\
\hline & Male & Female & Female & Male & & & \\
\hline & Engineer & Engineer & Engineer & Engineer & & & \\
\hline
\end{tabular}

* In groups 1 and 2, race and gender are categorical, age is continuous. The data are rescaled so that all of these are equivalent: 20 year difference in age, difference in gender, difference in race

Similarly, the distance between any two companies in different industries would be $\sqrt{2}$ and any two companies in the same industry would be a distance of zero apart. This would not be the case using only two dummy variables. For example, using one dummy variable for Agriculture and one dummy variable for Banking, the distance between an Agriculture company and a Banking company is $\sqrt{(1-0)^{2}+(0-1)^{2}}=\sqrt{2}$. However, the distance between an Agriculture company and a Computer Technology company is $\sqrt{(1-0)^{2}+(0-0)^{2}}=\sqrt{1}=1$. In this way, using only two (or more generally, c-1) dummy variables leads to inconsistencies in the distance measure. Binary categorical variables $(c=2)$ are a special case in which it is possible to obtain consistent distance measure using only one dummy variable.

\subsection{Measuring faultline distance}

To operationalize faultline distance, we used a distance score which measures how far apart the two subgroups are on demographic characteristics. This adds information about the potential group faultlines in the sense that faultline strength identifies the ways in which a group may subdivide, whereas faultline distance captures the degree of difference between two subgroups formed as a result of the strongest possible group split. In this, faultine distance provides information beyond what the measure of faultline strength may afford. The most obvious case where faultline distance is useful is when a group splits cleanly along all characteristics $(F a u=1)$ and faultline distance indicates how far apart the two subgroups are, thereby differentiating among groups with $F a u=1$. More generally, faultline strength helps differentiate among groups with the same Fau (not just $F a u=1$ ). It is possible for groups to have the same Fau measure but different distances, and the same distance measure but different Fau's (see examples in Tables 3 and 4 and discussion in the "Why do we need Distance?" section). 
Table 4 Examples of faultline measures in groups with categorical and continuous variables that showing that groups with the same faultline distance can have different faultline strength

\begin{tabular}{|c|c|c|c|c|c|c|c|}
\hline $\begin{array}{l}\text { Group } \\
\text { No. }\end{array}$ & Member A & Member B & Member C & Member D & $\begin{array}{l}\text { Faultline } \\
\text { Strength }\end{array}$ & $\mathrm{Fau}^{*}$ & Distance* \\
\hline \multirow[t]{4}{*}{1} & Black & Black & Black & Black & \multirow[t]{4}{*}{ Weak (1 align, 1 way) } & \multirow[t]{4}{*}{0.50} & \multirow[t]{4}{*}{1.0} \\
\hline & Male & Male & Male & Male & & & \\
\hline & 10 & 30 & 30 & 50 & & & \\
\hline & Sales & Sales & Sales & Sales & & & \\
\hline \multirow[t]{4}{*}{2} & White & Black & Black & White & \multirow[t]{4}{*}{ Weak (1 align, 2 ways) } & \multirow[t]{4}{*}{0.33} & \multirow[t]{4}{*}{1.0} \\
\hline & Male & Male & Male & Male & & & \\
\hline & 10 & 30 & 30 & 50 & & & \\
\hline & Sales & Sales & Sales & Sales & & & \\
\hline \multirow[t]{4}{*}{3} & White & Black & Black & White & \multirow[t]{4}{*}{$\begin{array}{l}\text { Moderate ( } 3 \text { align, } 1 \\
\text { way) }\end{array}$} & \multirow[t]{4}{*}{0.60} & \multirow[t]{4}{*}{1.73} \\
\hline & Male & Female & Female & Male & & & \\
\hline & 10 & 30 & 30 & 50 & & & \\
\hline & Sales & Secretary & Secretary & Sales & & & \\
\hline \multirow[t]{4}{*}{4} & White & Black & Black & White & \multirow[t]{4}{*}{ Strong ( 3 align, 1 way) } & \multirow[t]{4}{*}{0.96} & \multirow[t]{4}{*}{1.73} \\
\hline & Male & Female & Female & Male & & & \\
\hline & 25 & 30 & 30 & 35 & & & \\
\hline & Sales & Secretary & Secretary & Sales & & & \\
\hline
\end{tabular}

*Age is continuous. The data are rescaled so that a 20 year difference in age is equivalent to a difference in race, gender, or occupation

Our faultline distance measure is adapted from multivariate statistical cluster analysis (e.g., Morrison 1967; Jobson 1992; Sharma 1996) and is calculated as the distance between subgroup centroids (the Euclidean distance between the two sets of averages): $D_{g}=$ $\sqrt{\sum_{j=1}^{p}\left(\bar{x}_{\cdot j 1}-\bar{x}_{\cdot j 2}\right)^{2}}$, where the centroid (vector of means of each variable) for subgroup $1=\left(\bar{x}_{\cdot 11}, \bar{x}_{\cdot 21}, \bar{x}_{\cdot 31}, \ldots, \bar{x}_{\cdot p 1}\right)$ and the centroid for group $2=\left(\bar{x}_{\cdot 12}, \bar{x}_{\cdot 22}, \bar{x}_{\cdot 32}, \ldots, \bar{x}_{\cdot p 2}\right)$. Faultline distance can take on values between 0 and $\infty$, with larger values indicating a larger distance between the resulting subgroups. Faultline distance is reported, in our analyses, for the subgroup split with the maximum faultline strength.

Although faultline strength $(\mathrm{Fau})$ and faultline distance $(D)$ provide separate (though related) information about potential faultlines, and can be used as separate individual variables in an analysis, we believe faultline distance is most useful when it is conceptualized and consequently tested as a moderator of faultline strength. Consistent with our conceptualization of faultlines, we believe that only when we consider the two aspects of faultlines simultaneously (as with a multiplier form, or interaction) do we see the true effects of faultlines in groups. For example, an alignment of members (faultline strength) induces awareness of membership into separate and distinct subgroups. However, faultline distance moderates this relationship by escalating more antagonistic subgroup interactions in groups with large distance in which the members of one subgroup are extremely different from members of another subgroup (emphasis on differences). By multiplying the scores of strength and distance in the interaction term, we ensure that all information is considered. This extension of faultline framework provides a more comprehensive view of diversity and demographic alignment than those presented by previous work.

\subsection{Combining multiple attributes}

Because our faultline strength and distance measures allow researchers to combine measurements on many different variables, it is necessary to consider rescaling the raw data so 
that measurements are combined appropriately on a single common scale (Kaufman and Rousseeuw 1990, p. 11; Manly 1994, p. 134; Jobson 1992, p. 508). The use of some type of rescaling in this type of analysis is unavoidable. Obviously combining continuous and categorical data in a single measure requires careful thought as to how to combine these on a common scale. However, even at a more basic level, deciding on the levels for a categorical variable or the measurement units for a continuous variable also involve subjective judgments that can affect future analyses (e.g., Gibson and Vermeulen 2003; Shaw 2004; Kaufman and Rousseeuw 1990). For example, how can we combine a 15 year difference in age with a difference in gender on one common scale? However, it is also important when using only continuous variables (Kaufman and Rousseeuw 1990, Sect. 2.1). For example, how does a 15 year difference in age compare to a 10 year difference in tenure? These types of problems are common in the multivariate statistical cluster analysis literature, for example, and not at all unique to our faultline strength and distance measures. This idea of rescaling is particularly important when combining continuous and categorical variables.

There are a number of different approaches to the issue of rescaling. The first approach focuses on the examination of any taxonomic research related to the particular attributes under study (Morrison 1967; Shaw 2004). The idea is to use subject-matter-experts' judgments to weigh characteristics according to how important the researcher thinks they are to the analysis at hand. Another approach to rescaling is a standard statistical method that uses standard deviation as a basis for equating variables. In our empirical analyses, we have used a combination of these approaches. Specifically, all continuous variables were rescaled by their standard deviations, so a difference of one standard deviation apart in a continuous variable, say age, contributes one to the total distance between the two observations, and all dummy variables were rescaled by multiplying by $1 / \sqrt{2}$, so a difference on a categorical variable, say race, contributes one to the total distance between the two observations. (If the dummy variables are not rescaled, the usual 0-1 dummy variable coding will lead to a difference in a categorical variable contributing $\sqrt{2}$ to the distance between two observations, which effectively weights differences in categorical variables greater than without the rescaling.) This rescaling strategy implies that, for example, that the following differences are equivalent: a one standard deviation difference in age, a one standard deviation in tenure, a difference in gender, a difference in race.

\section{Hypothetical examples}

Table 2 reports the characteristics and faultline strength ${ }^{3}$ and distance for eight 4-member groups. For comparisons to Lau and Murnighan (1998), we also report for each group the counts of the number of attributes that align (denoted as "align") and the possible ways to subdivide the group on the basis of these attributes (denoted as "ways"). The strength of the faultine based on these classifications is also reported, based on the maximum number of attributes that align ( $4=$ very strong, $3=$ strong, $2=$ medium, $1=$ weak). Comparing groups 1 through 5, shows that as a subgroup division aligns on more attributes Fau gets stronger, indicating stronger faultlines. Comparing groups 2, 7, and 8, and, separately, groups 3, and 6 , shows that adding more "ways" in which the group can split decreases Fau (or Fau stays the same). The more "ways" the group can split, the more cross-group similarity there is, resulting in a weaker faultline. Hence a smaller Fau makes sense in this case. For example,

3 We report the Fau obtained by maximizing over all splits where each subgroup contains at least two members (avoiding subgroups consisting of a single member). 
consider groups 3 and 6 . In group 3, the group can split on gender and race (A \& B vs. C \& D). In group 6, the group can split on gender and race (A \& C vs. B \& D) or on age and occupation (A \& D vs. B \& C). These two faultlines are both weaker than the one in group 3, because if group 6 splits on gender and race, then members of each subgroup share similar age and occupation with members of the opposite subgroup (cross-group similarity). A similar situation holds if the group splits on age and occupation.

\subsection{Why do we need distance?}

Table 3 shows how distance captures an essential aspect of group faultiness that faultline strength fails to address. Table 3 shows two pairs of groups where the Fau measures are the same, but the distance measures are very different. Consider groups 1 and 2. Both have moderate faultline strength scores (0.75). Both groups have the strongest split on age and gender (both groups split: B, C vs. A, D). However, the group members in group 1 differ more from each other across subgroups than the members in group 2 since the distance in age between subgroups in group 1 (75 and 56 vs. 32 and 18) is larger than the distance in group 2 (65 and 63 vs. 35 and 37). Thus while the faultline strength scores are about the same for both groups, the strength score does not take into account the fact that the subgroups in group 1 are much farther apart than the subgroups in group 2. Our distance measure takes this into account and provides a metric of how far apart (conceptually different) these resulting subgroups are (2.26 vs. 1.72, respectively).

Distance is especially useful for complete faultline splits $(F a u=1.00)$. In this case the distance can distinguish between complete splits where the subgroups are fairly close together and those where they are far apart. Distance can even differentiate complete faultline splits when all variables are categorical. For examples compare groups 3 and 4 in Table 3. Even though both groups have Fau $=1.0$, the members of group 1 differ on 3 characteristics whereas the members of group 2 differ on only two. These differences are reflected in the distance scores (group 1 distance $=1.73$, group 2 distance $=1.41$ ). Similarly, groups can have the same distance measure, but different Faus (see Table 4). Therefore, Fau and distance are both separate (but related) important pieces of information.

\section{An empirical example}

The intent of this research is to develop and empirically illustrate the properties of our faultline measure. We collected data on two hundred two undergraduate students (50 four- and fiveperson groups) from an East Coast university. The mean age of the participants was 20.3 years (range $=17-22$ years). The plurality of the participants $(44.3 \%$ ) were White; $23.5 \%$ were Asian; $6.1 \%$ were Black; and $0.9 \%$ were Hispanic. Forty eight percent of the participants were female. We focus on five demographic attributes: race (e.g., Asian, White, etc.), gender, age, class (e.g., senior), and major (e.g., management, psychology) to examine their alignment as a cause of processes (conflict) and outcomes (satisfaction, perceived performance).

We measured faultline strength and distance along gender, age, race, class and educational major using the formula previously described. Faultline strength ranged from 0.333 to 1.000 in our dataset. Values of faultline distance ranged from 0.347 (weak faultline distance) to 16.567 (very strong faultline distance) in our dataset. We obtained the interaction term by multiplying the two scores. We assessed active group faultlines with four items ("My team split into subgroups," "My team broke into alliances," "My team cracked into smaller cliques," "My team divided into subsets of people") (Cronbach's $\alpha=0.88$ ). We asked what 
they split on with an additional open-ended question following the Likert items to verify that groups were splitting on demographics. Conflict (relationship-based) was measured using Jehn (1995) items for relationship conflict (Cronbach's $\alpha=0.80$ ). For example, "How much were personality clashes evident in your team?" We used self-reports to measure satisfaction (Cronbach's $\alpha=0.88$ ), and perceived performance (Cronbach's $\alpha=0.94$ ).

We examined the relationships between faultline aspects (strength, distance, and the interaction between strength and distance) and active faultlines using hierarchical linear modeling (HLM). Given that group faultlines are a multilevel phenomenon with observations at one level of analysis (individuals) nested within another level of analysis (groups; Harrison and Klein 2007), we employed two-level hierarchical linear modeling. We controlled for group heterogeneity of the demographic characteristics by including the Blau (1977) heterogeneity index for categorical variables (i.e., race, gender, major) and the coefficient of variation for continuous variables (e.g., age, class) (Allison 1978) as group-level predictors. When controlling for strength and distance, the interaction term was significantly and positively related to active faultlines $(y=0.26, p=0.026)$. The interaction was also positively related to conflict ( $y=0.12, p=0.048)$, and significantly and negatively associated with performance $(y=-0.27, p=0.028)$ and satisfaction $(y=-0.17, p=0.018)$.

\section{Discussion}

In this paper, we develop faultline measures to quantify how cleanly a group splits into two subgroups (faultline strength) and how far apart these subgroups are (faultline distance) on demographic characteristics. We believe that our faultline strength measure (Fau) closely reflects the original conceptualization of faultlines as defined by Lau and Murnighan (1998), as it captures how many demographic attributes align within a group (See Appendix 1 for comparison across different measures). More importantly, we also extend faultline framework and methodology by developing a measure of faultline distance and considering the extent to which subgroups diverge as a result of accumulated differences across aligned subgroups. This new, more elaborate conceptualization of faultlines was validated by presenting a number of hypothetical examples that demonstrate the distinct properties of potential faultline strength and distance. We also demonstrated the predictive properties of our measures on the actual perception of faultlines by group members in an empirical study. We found that the interaction of faultline strength and distance was the most statistically significant predictor of active faultlines; it predicted active divides over and above the standard diversity variables (group heterogeneity scores) or faultline strength and distance alone.

Other measures of faultlines have been recently proposed (e.g., Gibson and Vermeulen 2003; Li and Hambrick 2005; Shaw 2004). Shaw (2004) has developed an SPSS-based program to measure internal and cross-subgroup alignments along categorical attributes for up-to-six member groups. Gibson and Vermeulen (2003) have proposed two measures-team heterogeneity and subgroup strength - to capture the degree of overlap between members in a group. Barkema and Chvyrkov (2003) have offered a two-step approach in which a latent class technique allows to determine whether or not faultlines exist in teams and then Lau and Murnighan (1998) classification is employed to differentiate between weak and strong faultlines. Li and Hambrick (2005) have suggested using a minor modification of the $d$-statistic to measure the size of the overall demographic faultline between factions. While these measures might be conceptually and methodologically different, they are somewhat similar in capturing the alignment properties of groups through a two-step approach (see Appendix 1 for more detailed comparisons of our measures to other proposed faultline 
measures). Each measure has a number of advantages and limitations, some are still fairly complex, but most are in accord of a notion that more work should be done in developing a better operationalization of faultlines. Our Fau and distance measures have numerous desirable properties including the ability to accommodate both continuous and categorical variables, an unlimited number of variables, a theoretically unlimited group size, and different systems of rescaling and equating continuous and categorical variables. ${ }^{4}$

One of the assumptions made in our faultline strength and distance calculations is that each demographic attribute used in the faultline calculations should be treated as a separate characteristic. In other words, the measures do not adjust for highly correlated variables. For example, if age and tenure are highly correlated (all the experienced workers are old, all the new workers are young), then a faultline measure that includes both age and tenure, effectively "double counts" age and tenure. We can adjust for this using, for example, Mahalanobis distance in the Fau distance and generalized sum of squares (that account for the correlation between attributes) in the numerator and denominator of Fau (e.g., Jobson 1992, p. 218). However, if you view age and experience as two separate and distinct characteristics then double counting makes sense, so this decision will depend on the context of the analysis.

We have also assumed that a group will split into only two subgroups. Considering possible subdivisions into three or more groups adds considerable complication to the Fau strength calculations. For these calculations it would be necessary to use a statistical criterion, possibly borrowed from the statistical cluster analysis literature, to decide which split is the strongest split. Another possibility is to investigate the differences in faultline dynamics with respect to the subgroup size. For instance, we have only looked at subgroup splits, excluding oneperson (token) splits and recommended calculating faultline strength scores considering only splits in which each subgroup has at least two members, thus excluding "token" splits (i.e., subgroups consisting of only one member). The faultline framework as developed by Lau and Murnighan (1998) suggests that two competing subgroups may generate much intensity due to diametric opposition to one another; thus, we were interested in exploring these specific processes.

While there has been a growing interest in measuring faultlines, one of the challenges has been a lack of a sound method for quantifying group faultlines (Trezzini 2006). This paper proposed a method for studying faultlines and developed a faultline measure to quantify how cleanly a group splits into two subgroups (faultline strength) and how far apart these subgroups are (faultline distance) on demographic differences. We also verified the connection of potential faultlines to active or perceived faultlines.

\section{Appendix 1: Comparisons to other faultline measures}

Here we summarize faultline measures proposed by Shaw (2004), Gibson and Vermeulen (2003), and Barkema and Chvyrkov (2003) and compare them to our faultline strength and distance measure.

Shaw (2004) faultline measure can accommodate only categorical variables, unlike our measures that can accommodate both continuous and categorical variables. Including only categorical variables is undesirable because not only does it require forming subjective classes for continuous variables (e.g., young: 20-35, middle age 36-55, old: 56-70), but also

4 We have made our SAS-based code publicly available to make faultline calculations accessible and facilitate more empirical research. See http://webpages.scu.edu/ftp/bezrukova/faultlines.htm 
any measurements based on these categories will, for example, treat two people with ages 20 (young) and 55 (middle age) as equally different as two people with ages 35 (young) and 36 (middle age).

Gibson and Vermeulen (2003) measures of heterogeneity and subgroup strength are built on measures of "overlap". The "overlap" between each possible pair of members on a team is measured on each characteristic separately and summed. This aggregate measure of overlap is then used to calculate "team heterogeneity" and "subgroup strength". The overlap in categorical characteristics is either zero or one (for example, one if the pair shares the same race, zero if they don't). The overlap in continuous characteristics is measured as a percentage (for example, a pair with 4 and 5 years of tenure has 0.8 overlap, a pair with ages 20 and 25 has 0.8 overlap). This system makes the following assumptions: (1) The difference between members with 4 and 5 years of tenure is equivalent to the difference between, for example, members with ages of 20 and 25 . In other words, distance for continuous variables is nonlinear. (2) Members with a value of zero for a continuous variable are completely different than members with a nonzero value of that variable. For example, the difference between members with 0 (new hire) and 5 years of tenure, is equivalent to the difference between members of difference genders (or different races). Also the difference between 0 and 5 years of tenure is the same as the difference between 0 and 1 years, 0 and 2 years, 0 and 10 years, etc. since the overlap is always 0 . (3) All characteristics are equally important when calculating heterogeneity and subgroup strength. These assumptions are slightly different than the ones we make. In particular, unlike assumption (1) our distance is linear. We also do not single out the value of zero for a continuous variable for special treatment (assumption (2)) and we do not restrict ourselves to assumption (3), since our measures can accommodate any weighting of the group characteristics if some are judged to be more important than others for the analysis at hand Finally, although computationally quite simple to calculate, Gibson and Vermeulen's measures are sensitive to group size. ${ }^{5}$

Barkema and Chvyrkov (2003) use a "latent clustering procedure" to identify the existence of faultlines, and then use Lau and Murnighan (1998) classification of "ways" and "alignments" to classify the faultlines as weak or strong. The use of a latent clustering procedure (Dillon and Kumar 1994) requires numerous statistical modeling assumptions, not only for the exact distributional relationships between all of the variables involved, but also for the statistical criterion that is used to judge whether a faultline is "present" in the group. This represents a very different approach than Shaw (2004), Gibson and Vermeulen (2003), and Thatcher et al. (2003).

\section{References}

Allison, P.D.: Measures of inequality. Am. Soc. Rev. 43, 865-880 (1978)

Arsenault, P.M.: Validating generational differences: a legitimate diversity and leadership issue. Leadersh. Organ. Dev. J. 25, 124-141 (2004)

Barkema, H.G., Chvyrkov, O.: Does top management team diversity promote or hamper foreign expansion? Working paper, Tilburg University (2003)

Bedeian, A.G., Mossholder, K.W.: On the use of the coefficient of variation as a measure of diversity. Organ. Res. Methods 3, 285-297 (2000)

Blau, P.: Inequality and Composition: A Primitive Theory of Social Structure. New York Free Press, New York (1977)

5 Consider a 4 person group that splits cleanly into 2 versus 2 ( 4 characteristics): our $F a u=1.00, \mathrm{G} \& \mathrm{~V}$ heterogeneity $=0.75, \mathrm{G} \& \mathrm{~V}$ subgroup strength $=2.07$. Now consider a 16 person group that splits cleanly into 8 versus 8 ( 4 characteristics): our $F a u=1.00, \mathrm{G} \& \mathrm{~V}$ heterogeneity $=0.53, \mathrm{G} \& \mathrm{~V}$ subgroup strength $=2.00$. 
Dillon, W.R., Kumar, A. : Latent structure and other mixture models in marketing: an integrative survey and overview. In: Bagozzi, R.P. (ed.) Advanced Methods of Marketing Research, pp. 352-388. Blackwell, Cambridge (1994)

Gibson, C., Vermeulen, F.: A healthy divide: subgroups as a stimulus for team learning behavior. Adm. Sci. Q. 48, 202-239 (2003)

Harrison, D.A., Klein, K.J.: What's the difference? Diversity constructs as separation, variety, or disparity in organizations. Acad. Manag. Rev. 32(4), 1199-1228 (2007)

Jehn, K.A.: A multimethod examination of the benefits and detriments of intragroup conflict. Adm. Sci. Q. 40, 256-282 (1995)

Jehn, K.A., Northcraft, G., Neale, M.: Why differences make a difference: a field study of diversity, conflict, and performance in workgroups. Adm. Sci. Q. 44, 741-763 (1999)

Jobson, J.D.: Applied Multivariate Data Analysis, vol. II: Categorical and Multivariate Methods. Springer, New York (1992)

Kaufman, L., Rousseeuw, P.J.: Finding Groups in Data: An Introduction to Cluster Analysis. Wiley, New York, NY (1990)

Lau, D., Murnighan, J.K.: Demographic diversity and faultlines: the compositional dynamics of organizational groups. Acad. Manag. Rev. 23, 325-340 (1998)

Lau, D., Murnighan, J.K.: Interactions within groups and subgroups: the dynamic effects of demographic faultlines. Acad. Manag. J. 48, 645-659 (2005)

Li, J.T., Hambrick, D.C.: Factional groups: a new vantage on demographic faultlines, conflict, and disintegration in work teams. Acad. Manag. J. 48(5), 794-813 (2005)

Manly, B.F.J.: Multivariate Statistical Methods: A Primer. Chapman \& Hall, New York, NY (1994)

Molleman, E.: Diversity in demographic characteristics, abilities and personality traits: do faultlines affect team functioning? Group Decis. Negot. 14, 173-193 (2005)

Morrison, D.G.: Measurement problems in cluster analysis. Manag. Sci. 13, B775-B780 (1967)

Polzer, J.T., Milton, L.P., Swann, W.B.: Capitalizing on diversity: interpersonal congruence in small work groups. Adm. Sci. Q. 47, 296-324 (2002)

Riordan, C.M., Shore, L.M.: Demographic diversity and employee attitudes: an empirical examination of relational demography within work units. J. Appl. Psychol. 82, 342-358 (1997)

Sawyer, J.E., Houlette, M.A., Yealey, E.L.: Decision performance and diversity structure: comparing faultlines in convergent, crosscut, and racially homogeneous groups. Organ. Behav. Hum. Decis. Process. 99, $1-15$ (2006)

Sharma, S.: Applied Multivariate Techniques. Wiley, New York (1996)

Shaw, J.B.: The development and analysis of a measure of group faultlines. Organ. Res. Methods 7(1), 66-100 (2004)

Teachman, J.D.: Analysis of population diversity. Sociol. Methods Res. 8, 341-362 (1980)

Thatcher, S.M.B., Jehn, K.A., Zanutto, E.: Cracks in diversity research: the effects of faultlines on conflict and performance. Group Decis. Negot. 12, 217-241 (2003)

Trezzini, B.: Probing the group faultline concept: an evaluation of measures of patterned multi-dimensional group diversity. Qual. Quant. 42, 339-368 (2006) 